\title{
Perdas de nitrogênio de dejeto líquido de suínos por volatilização de amônia ${ }^{1}$
}

\author{
Nitrogen lost by ammonia volatilization from pig slurry
}

\author{
Claudir José Basso ${ }^{2}$ Carlos Alberto Ceretta ${ }^{3}$ Paulo Sérgio Pavinato ${ }^{4}$ \\ Márcio José da Silveira ${ }^{5}$
}

\section{RESUMO}

A volatilização de amônia é umas das principais formas de perdas de nitrogênio, especialmente com a aplicação de dejetos, devido a sua distribuição a lanço, em superfície. Este trabalho teve por objetivo determinar as perdas de $N$ por volatilização de amônia em função de doses e horários de aplicação de dejeto líquido de suínos. O trabalho foi conduzido a campo em fevereiro, maio, outubro e dezembro de 2001, sendo que, em fevereiro e dezembro, aplicou-se o dejeto em dois horários $\left(10\right.$ e 18h). As doses testadas foram 0, 20, 40 e $80 \mathrm{~m}^{3} \mathrm{ha}$ ${ }^{1}$ e as determinações das perdas de amônia foram feitas às 3, 6 , $12,24,30,36,42,48,60,72,96,120$, e 144 horas após a aplicação do dejeto, totalizando um período de avaliação de seis dias. $O$ uso de menores doses de dejeto líquido de suínos minimizou as perdas de $N$ por volatilização de amônia. Os picos de perda ocorreram nas primeiras horas após a aplicação indicando que, quando possível, a sua incorporação seria uma alternativa à diminuição nas perdas de $N$ por volatilização de amônia. $O$ horário de aplicação do dejeto não afetou de maneira consistente as perdas de $N$ por volatilização de amônia.

Palavras - chave: esterco, resíduos orgânicos, dejetos de animais, adubação orgânica.

\section{ABSTRACT}

Ammônia volatilization is one of the main mechanisms of soil nitrogen loss, especially associated with application of pig slurry on soil surface. The objectives of this study were to determine the ammonia volatilization after soil application of pig slurry in soil surface, at different times of the year and hour of application. The pig slurry was spread over the soil surface in February, May, October and December. In February and December the ammonia volatilization was also evaluated for application at 10:00 AM and 6:00 PM. The rates tested were 0, 20, 40 and $80 \mathrm{~m}^{3} \mathrm{ha}^{-1}$ and the determination of ammonia loss were made at 3, 6, 12, 24, 30, 36, 42, 48, 60, 72, 96, 120, and 144 hours after the slurry application, adding up to six days of loss evaluation. Minimum ammonia volatilization was achieved with small amount of pig slurry application. The largest losses peaks were observed in the few hours following application indicating that, whenever possible, its soil incorporation would be an option to decrease $N$ loss. The application time was not a consistent solution to the ammonia volatilization problem.

Key words: manure, crop residue, organic fertilizer, animal waste.

\section{INTRODUÇÃO}

$\mathrm{O}$ nitrogênio $(\mathrm{N})$ é um dos nutrientes encontrados em maior proporção no dejeto líquido de suínos. Na maioria dos casos, cerca de $50 \%$ desse $\mathrm{N}$ encontra-se na forma mineral, podendo ocorrer perdas de $\mathrm{N}$ por volatilização na forma de amônia $\left(\mathrm{NH}_{3}\right)$, que além de poluir o ar também diminui o potencial fertilizante do dejeto. As perdas de $\mathrm{N}$ por volatilização podem ocorrer quando os dejetos de suínos são armazenados por longos períodos (SCHERER et al., 1995), e principalmente, após aplicação no campo. Por ser um gás em condições normais de temperatura e pressão atmosférica, a amônia presente no solo, na água, fertilizantes e estercos, pode rapidamente volatilizar para a atmosfera e reagir rapidamente com prótons, metais e compostos ácidos para formar íons ou compostos que variam em estabilidade.

Os porcentuais de perda de $\mathrm{N}$ por volatilização de amônia dependem das características do dejeto e do ambiente e podem, segundo GORDON et al. (1988) e THOMPSON et al. (1990), ser pequenos

\footnotetext{
${ }^{1}$ Parte da Tese de Doutorado do primeiro autor apresentada ao Programa de Pós-graduação em Agronomia, Área de Biodinâmica do Solo, Universidade Federal de Santa Maria (UFSM). Trabalho parcialmente financiado pelo Conselho Nacional de Desenvolvimento Científico e Tecnológico (CNPq), Fundação de Amparo a Pesquisa do Rio Grande do Sul (FAPERGS) e Programa de Núcleos de Excelência (PRONEX).

${ }^{2}$ Engenheiro Agrônomo, Doutor, SLC Agrícola Ltda, 97620-010, Porto Alegre, RS. E-mail: cjbasso@bol.com.br

${ }^{3}$ Engenheiro Agrônomo, Doutor, Professor Titular, Departamento de Solos, UFSM, 97105-900, Santa Maria, RS. Bolsista do CNPq. Email: ceretta@ccr.ufsm.br. Autor para correspondência.

${ }^{4}$ Engenheiro Agrônomo, Doutorando na Universidade Estadual de São Paulo, Faculdades de Ciências Agronômicas, Departamento de Produção Vegetal, 18603-970, Botucatu, SP. E-mail: pspavinato@mail.ufsm.br

${ }^{5}$ Engenheiro Agrônomo, Mestre, Weisul Agrícola Ltda, 98920-000, Horizontina, RS

E-mail: mjsilveira@bol.com.br
} 
ou até superiores a $90 \%$ do $\mathrm{N}$ mineral aplicado. Dejetos com maiores teores de matéria seca favorecem as perdas de $\mathrm{N}$ por volatilização. Contudo, aplicar dejetos sobre uma superfície com presença de plantas que diminuem a velocidade do vento pode diminuir as perdas de amônia (Sommer et al., 1997).

O horário de aplicação também pode afetar a quantidade de $\mathrm{N}$ volatilizado. Exemplo disso é o trabalho de MOAL et al. (1995), os quais observaram que cerca de $75 \%$ das perdas de $\mathrm{NH}_{3}$ ocorreram até $15 \mathrm{~h}$ após a aplicação do dejeto e diminuíram a partir da aplicação ao meio dia, no entardecer e próximo à meia noite. Esses autores atribuíram as diferenças observadas na volatilização de amônia às variações na temperatura do ar e do solo e o teor de matéria seca e de $\mathrm{N}$ amoniacal (mineral) do dejeto.

A incorporação imediata do dejeto diminui as perdas de N por volatilização de amônia (BLESS et al., 1991). Entretanto, a incorporação do dejeto não é realizada na maioria das propriedades onde o plantio direto é adotado.

O objetivo do trabalho foi determinar as perdas de $\mathrm{N}$ por volatilização de amônia com doses, épocas do ano e horários de aplicação de dejeto líquido de suínos.

\section{MATERIAL E MÉTODOS}

O trabalho foi realizado na Universidade Federal de Santa Maria, em Argissolo Vermelho Distrófico arênico, com as seguintes características na camada de $0-10 \mathrm{~cm}$ : argila $240 \mathrm{gkg}^{-1} ; \mathrm{pH}$ (em água) 4,70; matéria orgânica $16 \mathrm{gkg}^{-1} ; 15,0$ e $96 \mathrm{mgdm}^{-3}$ de P e K, respectivamente; $0,8,2,7$ e $1,1 \mathrm{cmol}_{\mathrm{c}} \mathrm{dm}^{-3} \mathrm{de} \mathrm{Al}$, Ca e $\mathrm{Mg}$, respectivamente.

Foram aplicadas as doses 0, 20, 40 e $80 \mathrm{~m}^{3} \mathrm{ha}^{-1}$ de dejeto líquido de suínos, em fevereiro, maio, outubro e dezembro de 2001, em superfície, em área sob plantio direto e onde havia uma quantidade de palha de aveia de $3,4,2,8,3,7$ e 3,0 $\mathrm{Mg} \mathrm{ha}{ }^{-1}$, respectivamente. $\mathrm{O}$ dejeto foi coletado em uma unidade de produção de leitão do Condomínio de Suinocultores em Paraíso do Sul, RS. O dejeto apresentava pelo menos 30 dias em tanque de fermentação/armazenamento. Em todas as épocas, a aplicação foi feita às $10 \mathrm{~h}$. Em fevereiro e dezembro, que são os períodos mais quentes do ano, o dejeto também foi aplicado às $18 \mathrm{~h}$. Os tratamentos foram arranjados em blocos ao acaso, com quatro repetições. As características dos dejetos são apresentadas na tabela 1 .

As quantidades de amônia volatilizadas foram determinadas às $3,6,12,24,30,36,42,48$,
Tabela 1 - Características do dejeto de suíno utilizado em cada época de aplicação.

\begin{tabular}{lcccc}
\hline \begin{tabular}{c} 
Características do \\
\multicolumn{1}{c}{ dejeto ${ }^{(1)}$}
\end{tabular} & \multicolumn{4}{c}{ Épocas de aplicação e avaliação } \\
fevereiro & maio & outubro & dezembro \\
\hline $\mathrm{pH}$ & 7,10 & 7,30 & 6,60 & 7,40 \\
Matéria seca - \% & 6,50 & 1,86 & 9,94 & 8,85 \\
$\mathrm{~N}_{\text {-total - \% }}$ & 0,65 & 0,11 & 0,75 & 0,46 \\
$\mathrm{NH}_{4}{ }^{+}$- \% & 0,39 & 0,05 & 0,30 & 0,33 \\
$\mathrm{NH}_{4}{ }^{+} / \mathrm{N}$-total- \% & 60 & 47 & 40 & 72 \\
\hline
\end{tabular}

(1) Dados obtidos em base úmida. As quantidades de $\mathrm{N}$ mineral aplicadas com a dose de $20 \mathrm{~m}^{3} \mathrm{ha}^{-1}$ correspondem a $78,10,60$ e $66 \mathrm{~kg} \mathrm{ha}^{-1}$, com as aplicações feitas em fevereiro, maio, outubro e dezembro, respectivamente.

60, 72, 96, 120 e 144h após a aplicação do dejeto, totalizando um período de seis dias. $\mathrm{O} \mathrm{pH}$ e os teores de $\mathrm{N}$ total e $\mathrm{N}$ mineral $\left(\mathrm{NH}_{4}{ }^{+}\right)$foram determinados no dejeto "in natura" (fração líquida + pastosa). Fezse a separação das frações líquida e pastosa, pela centrifugação de aproximadamente $50 \mathrm{~g}$ de dejeto durante 20 minutos a 2500rpm (1027g), segundo SCHERER et. al., (1996). O N mineral do dejeto foi determinado utilizando-se destilador de arraste de vapor semi-micro Kjeldahl (TEDESCO et al., 1995). Na determinação do N total do dejeto "in natura", utilizou-se o método descrito por TEDESCO et al. (1995), mas sem a utilização de $\mathrm{H}_{2} \mathrm{O}_{2}$.

A instalação dos coletores de amônia no campo iniciou um mês antes da instalação do experimento, quando anéis de PVC com 190mm de diâmetro e $70 \mathrm{~mm}$ de altura foram fixados ao solo a uma profundidade de $40 \mathrm{~mm}$. Nas áreas dos anéis o dejeto foi aplicado manualmente e, imediatamente após foram acoplados os coletores de $\mathrm{NH}_{3}$ do tipo semi-aberto estático, modificado de NÖMMIK (1973), os quais foram construídos com tubos de PVC (branco) de $200 \mathrm{~mm}$ de diâmetro e $360 \mathrm{~mm}$ de altura. Nos coletores eram colocados dois discos de espuma (20mm de espessura e densidade 28) apoiados sobre estrutura metálica. No disco inferior era retida a $\mathrm{NH}_{3}$ proveniente do solo e no superior a $\mathrm{NH}_{3}$ da atmosfera, evitando que esta última interferisse nos resultados. Previamente os discos de espuma eram preparados em laboratório e acondicionados em sacos plásticos $(5 \mathrm{~kg})$ com $100 \mathrm{~mL}$ de uma solução contendo $50 \mathrm{~mL}$ de $\mathrm{H}_{3} \mathrm{PO}_{4}$ e $40 \mathrm{~mL}$ de glicerol por litro, sendo comprimidos dentro dos sacos plásticos até reterem aproximadamente $70 \mathrm{~mL}$ da solução. Após cada retirada, os discos eram acondicionados em sacos plásticos, fechados e levados ao laboratório, para lavagem com solução de $\mathrm{KCl} 1 \mathrm{~mol} \mathrm{~L}^{-1}$. Essa solução 
foi coletada em balões de $500 \mathrm{~mL}$, de onde era retirada uma alíquota de $20 \mathrm{~mL}$ para determinação do teor de $\mathrm{NH}_{3}$ em destilador de arraste de vapor semi-micro Kjeldahl (TEDESCO et al., 1995). Foram instalados três geotermômetros a $20 \mathrm{~mm}$ de profundidade em cada tratamento para determinação da temperatura do solo no interior dos coletores no momento de cada coleta. Maiores detalhes da metodologia utilizada podem ser obtidos em BASSO (2003).

A comparação das médias de volatilização de amônia nos horários de aplicação foi feita pelo teste de Duncan a $5 \%$ de probabilidade de erro e o efeito das doses de dejeto em cada época de aplicação foi avaliado por meio de análise de regressão linear simples.

\section{RESULTADOS E DISCUSSÃO}

As perdas acumuladas de $\mathrm{N}$ por volatilização de $\mathrm{NH}_{3}$ durante seis dias após aplicação do dejeto variaram de 19 a $39 \%$ nos meses de fevereiro, outubro e dezembro. Em maio, essas perdas foram menores, provavelmente devido ao baixo teor de $\mathrm{N}$ no dejeto utilizado, como conseqüência de seu baixo teor de matéria seca (Tabela 2). As menores temperaturas em maio (Tabela 3) também contribuíram para diminuir as perdas de $\mathrm{N}$ por volatilização.

$\mathrm{O}$ alto porcentual médio de perdas de $\mathrm{N}$ por volatilização de $\mathrm{NH}_{3}$ em dezembro (33\%), foi favorecido pelas altas temperaturas máximas e mínimas e pelo teor de matéria seca de $8,85 \%$ do dejeto, que pode ser considerado alto, porque SCHERER et al. (1995) mostraram que quase 50\% das 98 amostras de dejeto líquido de suínos coletadas no Oeste Catarinense apresentavam teores de matéria seca inferiores a $2 \%$. Além disso, no dejeto aplicado em dezembro havia o maior porcentual de $\mathrm{N}$ mineral em relação ao $\mathrm{N}$ total (Tabela 1), o que significa que até $72 \%$ do $\mathrm{N}$ do dejeto poderia potencialmente volatilizar. Assim, as maiores temperaturas nos períodos mais quentes do ano podem, também, potencializar as perdas de $\mathrm{N}$ por volatilização, porque favorecem a decomposição do dejeto nas unidades de fermentação/armazenamento, proporcionando maiores quantidades de $\mathrm{N}$ mineral $\left(\mathrm{NH}_{4}{ }^{+}\right)$em relação ao $\mathrm{N}$ total. Isso pode ser observado na tabela 1, a qual demonstra que, nos meses mais quentes do ano, os porcentuais de $\mathrm{N}$ mineral $\left(\mathrm{NH}_{4}\right)$, em relação ao $\mathrm{N}$ total, foram de 60 e $72 \%$ para fevereiro e dezembro, respectivamente, e de 47 e $40 \%$ para maio e outubro, respectivamente, que são meses com menores temperaturas (Tabela 3 ).

$\mathrm{Na}$ avaliação feita em outubro, as perdas de $\mathrm{N}$ por volatilização foram inferiores àquelas de fevereiro e dezembro, mesmo o dejeto possuindo maior teor de matéria seca. Isso pode estar associado às menores temperaturas do ar, menor concentração de $\mathrm{N}$ mineral (40\%) em relação ao $\mathrm{N}$ total do dejeto e ao menor $\mathrm{pH}$ do dejeto $(6,60)$. $\mathrm{O} \mathrm{pH}$ do dejeto é responsável pelo equilíbrio $\mathrm{NH}_{4}{ }^{+} / \mathrm{NH}_{3}$ e quando $\mathrm{NH}_{3}$ é perdida por volatilização, irá ocorrer uma dissociação do íon $\mathrm{NH}_{4}{ }^{+}\left(\mathrm{NH}_{3}+\mathrm{H}^{+}\right)$diminuindo o $\mathrm{pH}$ e conseqüentemente a volatilização. Isso foi demonstrado por MACKENZIE \& TOMAR (1987), os quais observaram rápido decréscimo nas perdas de $\mathrm{NH}_{3}$ quando o $\mathrm{pH}$ do dejeto foi inferior a 6,0 . Contudo, após sua aplicação a campo será o pH do solo o fator mais importante nesta relação, porque o $\mathrm{NH}_{4}$ predomina em solos de menor $\mathrm{pH}$, enquanto que é maior a quantidade de $\mathrm{NH}_{3}$ em meio com $\mathrm{pH}$ mais elevado.

As perdas de amônia foram incrementadas à medida que houve um aumento na quantidade de dejeto aplicado (Figura 1), embora isso tenha ficado

Tabela 2 - Perdas acumuladas de amônia em 144 horas (seis dias) após aplicação do dejeto em cada época do ano ${ }^{(1)}$

\begin{tabular}{|c|c|c|c|c|c|c|c|c|c|}
\hline \multirow{3}{*}{$\begin{array}{l}\text { Doses de } \\
\text { dejeto } \\
\mathrm{m}^{3} \mathrm{ha}^{-1}\end{array}$} & \multicolumn{8}{|c|}{ Épocas de aplicação do dejeto } & \multirow[b]{2}{*}{ Média } \\
\hline & \multicolumn{2}{|r|}{ fevereiro } & \multicolumn{2}{|r|}{ maio } & \multicolumn{2}{|c|}{ outubro } & \multicolumn{2}{|c|}{ dezembro } & \\
\hline & & & & & & $\left.\mathrm{ha}^{-1}\right)$ & & & \\
\hline 0 & 1,1 & & 1,6 & & 2,0 & & 2,5 & & 1,8 \\
\hline 20 & 14,9 & $(19)^{(2)}$ & 2,2 & (23) & 15,2 & $(25)$ & 15,0 & $(23)$ & $11,8(23)$ \\
\hline 40 & 36,0 & (23) & 3,4 & (16) & 25,1 & (21) & 48,8 & (37) & $28,3(24)$ \\
\hline 80 & 81,0 & (26) & 6,4 & (15) & 53,3 & (22) & 102,9 & (39) & $60,9(26)$ \\
\hline Média & 33,0 & (23) & 3,4 & (18) & 23,9 & (23) & 42,3 & (33) & \\
\hline
\end{tabular}

(1) Aplicação do dejeto feita pela parte da manhã (10h).

${ }^{(2)}$ Representam a porcentagem das perdas de $\mathrm{NH}_{3}$ em relação à quantidade de $\mathrm{N}$ mineral $\left(\mathrm{NH}_{4}{ }^{+}\right)$aplicado. 
Tabela 3 - Temperaturas máximas e mínimas diárias do ar durante as determinações de perdas de $\mathrm{NH}_{3}$, nas épocas de aplicação de dejeto ${ }^{(1)}$.

\begin{tabular}{|c|c|c|c|c|c|c|c|c|}
\hline \multirow{2}{*}{$\begin{array}{l}\text { Período de } \\
\text { avaliação }\end{array}$} & \multicolumn{8}{|c|}{ Épocas de aplicação de dejeto } \\
\hline & \multicolumn{2}{|c|}{ fevereiro } & \multicolumn{2}{|c|}{ maio } & \multicolumn{2}{|c|}{ outubro } & \multicolumn{2}{|c|}{ dezembro } \\
\hline \multirow[t]{2}{*}{ dia } & & & & Tempera & & & & \\
\hline & máxima & mínima & máxima & mínima & máxima & mínima & máxima & mínima \\
\hline $1^{o}$ & 33 & 19 & 18 & 9 & 24 & 8 & 30 & 15 \\
\hline $2^{\circ}$ & 34 & 20 & 19 & 8 & 25 & 10 & 30 & 16 \\
\hline $3^{\circ}$ & 30 & 18 & 21 & 8 & 23 & 14 & 28 & 19 \\
\hline $4^{\circ}$ & 31 & 20 & 23 & 10 & 21 & 15 & 26 & 21 \\
\hline $5^{\circ}$ & 33 & 20 & 21 & 12 & 21 & 13 & 31 & 20 \\
\hline $6^{\circ}$ & 29 & 21 & 22 & 14 & 26 & 12 & 33 & 19 \\
\hline Média & 31,7 & 19,5 & 20,7 & 10,2 & 23,3 & 12,0 & 29,7 & 18,3 \\
\hline
\end{tabular}

${ }^{(1)}$ Dados obtidos na estação meteorológica da Universidade Federal de Santa Maria, RS.

menos evidente no dejeto aplicado no mês de maio, devido à pequena quantidade de $\mathrm{N}$ mineral aplicada (Tabela 1). Isso evidencia que o uso de doses menores de dejetos pode ser mais eficiente à produção vegetal. Deve-se ressaltar que as perdas de $\mathrm{NH}_{3}$ podem estar subestimadas pelo uso de coletor semi-aberto estático, conforme mencionam LARA \& TREVELIN (1990). Isso se deve principalmente pelas dificuldades às trocas gasosas no interior dos coletores, podendo subestimar as perdas em torno de $28 \%$, conforme relata DA ROS (2004), após efetuar uma revisão sobre o assunto.

A temperatura do ar correlacionou-se com as perdas de $\mathrm{NH}_{3}$ somente nas primeiras 24h após a aplicação do dejeto apresentando coeficientes de determinação $\left(\mathrm{r}^{2}\right)$ de 0,82 e 0,52 , respectivamente, sendo essa correlação $(\mathrm{p}<0,05)$ também encontrada por SOMMER \& OLSEN (1991). Esses autores obtiveram uma correlação positiva entre as perdas de $\mathrm{NH}_{3}$ e a temperatura do ar imediatamente após a aplicação do dejeto. Contudo, em períodos mais longos pode não haver alta correlação entre a temperatura do ar e as perdas de $\mathrm{NH}_{3}$ (BRUNKE et al., 1988).

Os picos de perdas de $\mathrm{NH}_{3}$ em fevereiro ocorreram em torno de $24 \mathrm{~h}$ após a aplicação, atingindo 50,53 e $45 \%$ do total de perdas ocorridas até seis dias após a aplicação com o uso de 20,40 e $80 \mathrm{~m}^{3} \mathrm{ha}^{-1}$ de dejeto, respectivamente (Figura 2a). Essas perdas aumentaram para 70,71 e $68 \%$ em torno de $48 \mathrm{~h}$. Isso pode ser devido às maiores temperaturas máximas e mínimas ocorridas em fevereiro, logo após a aplicação do dejeto (Tabela 3). Por outro lado, os picos de perdas

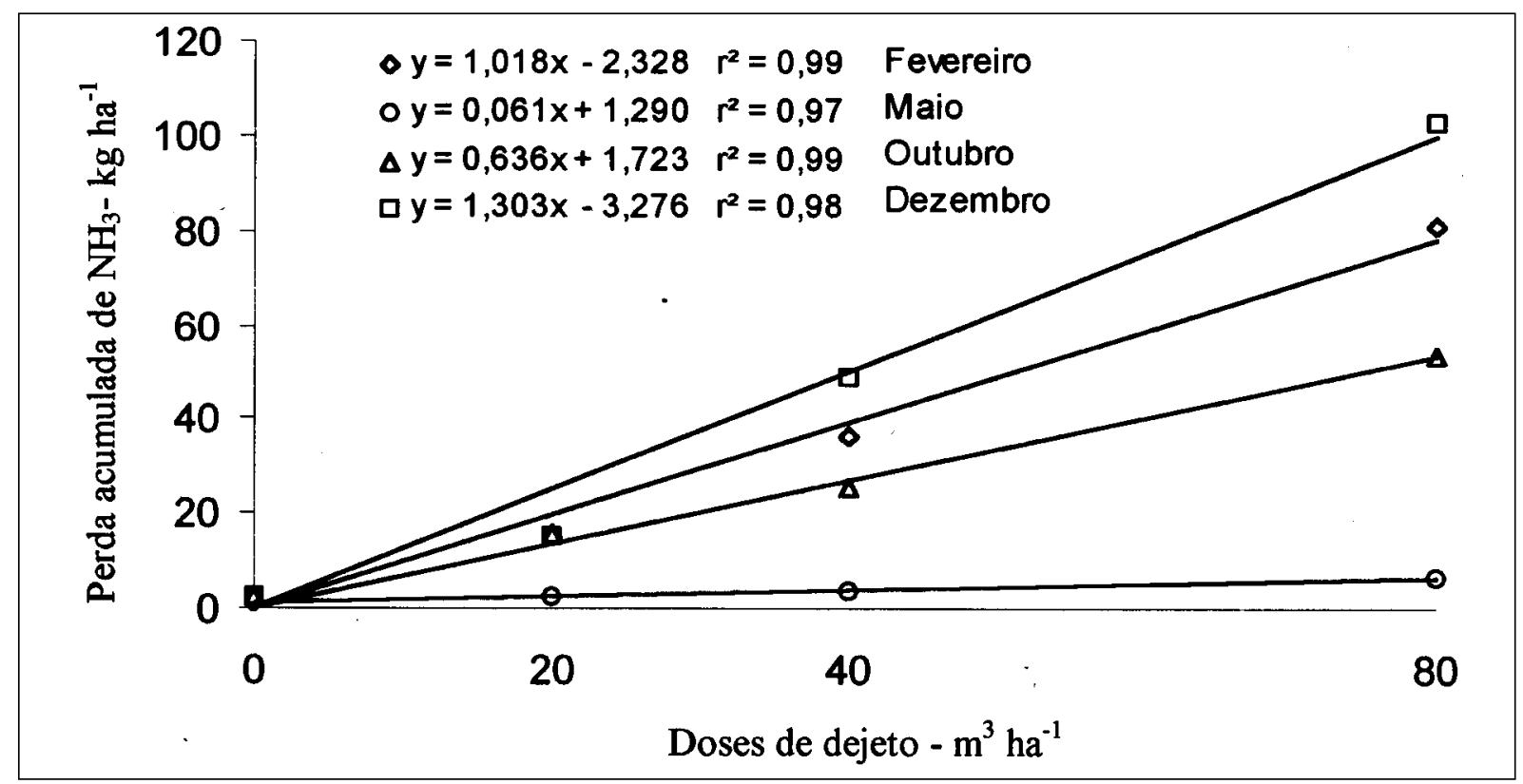

Figura 1 - Perdas acumuladas de $\mathrm{NH}_{3}$ nas doses de dejeto de suínos para os meses de fevereiro, maio, outubro e dezembro.

Ciência Rural, v.34, n.6, nov-dez, 2004. 


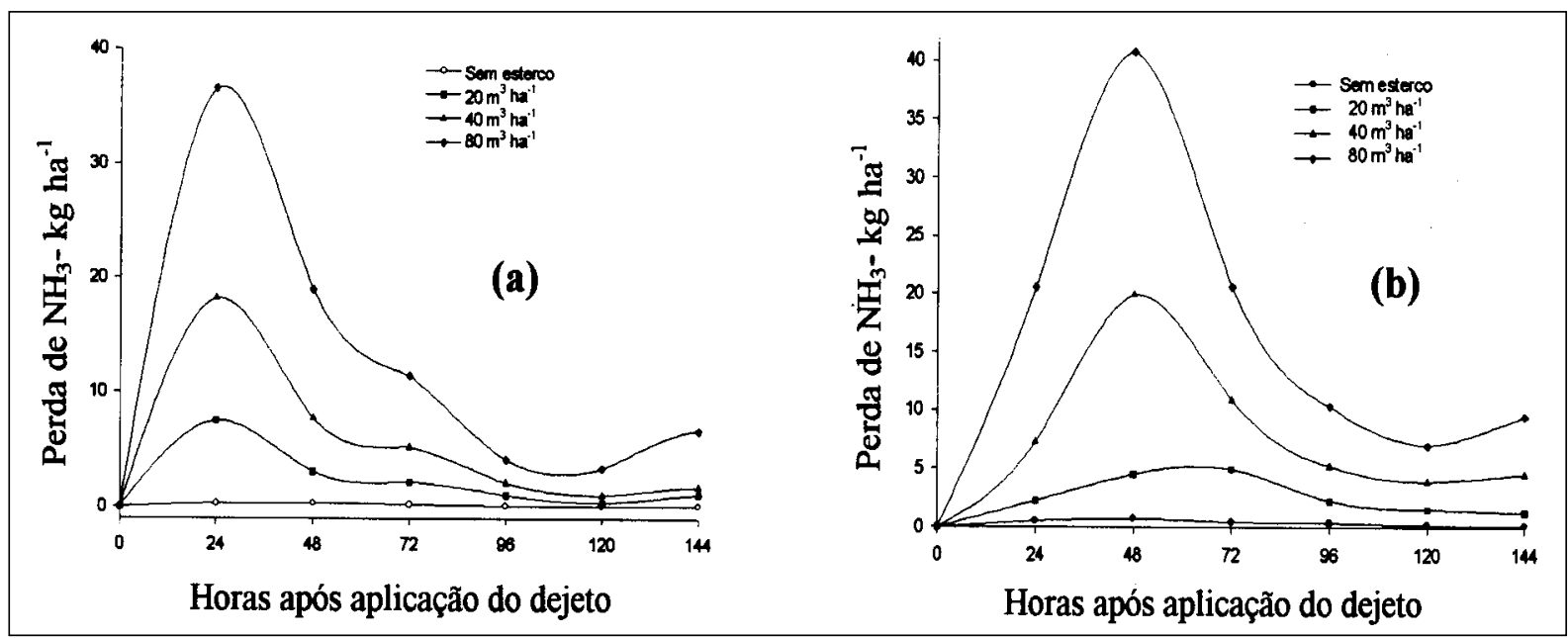

Figura 2 - Variação das perdas de amônia com o uso de dejeto de suínos nos meses de fevereiro (a) e dezembro (b).

de $\mathrm{NH}_{3}$ em dezembro ocorreram em torno 48 h após a aplicação, atingindo 45,56 e $59 \%$ do total de perdas ocorridas até seis dias após a aplicação com o uso de 20, 40 e $80 \mathrm{~m}^{3} \mathrm{ha}^{-1}$ de dejeto, respectivamente, comparado com 15,15 , e $19 \%$ nas primeiras $24 \mathrm{~h}$ (Figura 2b).

O horário de aplicação do dejeto somente influenciou as perdas de $\mathrm{NH}_{3}$ com a aplicação de $80 \mathrm{~m}^{3}$ ha ${ }^{1}$ no mês de fevereiro, quando as perdas acumuladas durante os seis dias foram maiores com a aplicação às 18h (Tabela 4). Em algumas situações, os porcentuais de perdas de $\mathrm{NH}_{3}$ foram maiores com aplicação do dejeto às $18 \mathrm{~h}$, principalmente para doses de dejeto de $40 \mathrm{~m}^{3}$ ha ${ }^{1}$ ou maiores. Por outro lado, MOAL et al. (1995) encontraram $83 \%$ de perdas de $\mathrm{NH}_{3}$ com a aplicação ao meio dia, em comparação com $43 \%$ quando aplicaram ao entardecer e zero de perda ao aplicarem à meia noite. Embora tenham utilizado dejeto líquido de bovinos, proveniente de gado leiteiro, BEAUCHAMP et al. (1982) também obtiveram as maiores perdas de $\mathrm{NH}_{3}$ com aplicação próxima do meio dia, em comparação com o dejeto aplicado no início da manhã. No entanto, deve-se considerar que, no trabalho de MOAL et al., (1995) as temperaturas diurnas médias foram ao redor de $20^{\circ} \mathrm{C}$, sendo inclusive próxima de $0^{\circ} \mathrm{C}$ à meia noite, enquanto que, no presente trabalho, a temperatura média das mínimas diárias foi de 20 e $18^{\circ} \mathrm{C}$ e a média das máximas diárias de 32 e $30^{\circ} \mathrm{C}$ para os meses de fevereiro e dezembro, respectivamente.

A temperatura do solo em dezembro, no momento da aplicação do dejeto às $10 \mathrm{~h}$, foi de $25^{\circ} \mathrm{C}$ a $20 \mathrm{~mm}$ de profundidade, e os porcentuais de perdas de $\mathrm{NH}_{3}$ foram menores do que quando o dejeto foi aplicado às $18 \mathrm{~h}$, quando a temperatura no solo foi de $30^{\circ} \mathrm{C}$. Quando o esterco foi aplicado às $10 \mathrm{~h}$, o solo na superfície está num processo inicial de aquecimento, já que toda a energia armazenada no dia anterior foi perdida durante a noite. Assim, as menores perdas de $\mathrm{N}-\mathrm{NH}_{3}$ com aplicação do esterco às $10 \mathrm{~h}$ podem estar associadas com as menores temperaturas do solo neste horário, com a aplicação de esterco com alto teor de água, que pode contribuir para o abaixamento da temperatura do solo, bem como o sistema de coletores que não permite a radiação global incidente sobre a superfície onde foi aplicado o esterco, que neste caso poderia favorecer as perdas com a aplicação às $10 \mathrm{~h}$.

Tabela 4 - Perdas acumuladas de amônia com doses de dejeto aplicadas em fevereiro e dezembro, em dois horários diários.

\begin{tabular}{|c|c|c|c|c|c|c|}
\hline \multirow[t]{2}{*}{ Época de aplicação } & \multirow[t]{2}{*}{ Horário de aplicação } & \multicolumn{4}{|c|}{ Doses de dejeto $\left(\mathrm{m}^{3} \mathrm{ha}^{-1}\right)$} & \multirow[b]{2}{*}{ Média } \\
\hline & & 0 & 20 & 40 & 80 & \\
\hline Fevereiro & $\begin{array}{l}10 \mathrm{~h} \\
18 \mathrm{~h} \\
\end{array}$ & $\begin{array}{l}1,1 \mathrm{~A}^{(1)} \\
1,2 \mathrm{~A} \\
\end{array}$ & $\begin{array}{l}14,9 \text { A }(19)^{(2)} \\
14,7 \mathrm{~A}(19)\end{array}$ & $\begin{array}{l}\mathrm{NH}_{3}\left(\mathrm{~kg} \mathrm{ha}^{-1}\right) \\
36,0 \mathrm{~A}(23) \\
45,5 \mathrm{~A}(29) \\
\end{array}$ & $\begin{array}{l}81,0 \text { A (26) } \\
90,0 \text { B (29) }\end{array}$ & $\begin{array}{l}33,0(23) \\
38,0(26) \\
\end{array}$ \\
\hline Dezembro & $\begin{array}{l}10 \mathrm{~h} \\
18 \mathrm{~h}\end{array}$ & $\begin{array}{l}2,5 \mathrm{~A} \\
2,5 \mathrm{~A}\end{array}$ & $\begin{array}{l}15,0 \text { A (23) } \\
19,9 \text { A (30) }\end{array}$ & $\begin{array}{l}48,8 \mathrm{~A}(37) \\
54,0 \mathrm{~A}(41)\end{array}$ & $\begin{array}{l}102,9 \text { A (39) } \\
116,0 \text { A (44) }\end{array}$ & $\begin{array}{l}42,0(33) \\
48,0(38)\end{array}$ \\
\hline
\end{tabular}

(1) Médias seguidas da mesma letra na coluna, para cada época de aplicação de dejeto, não diferem pelo teste de Duncan a 5\% de probabilidade de erro.

${ }^{(2)}$ Representam perdas de amônia em porcentagem, em relação à quantidade total de $\mathrm{N}$ mineral $\left(\mathrm{NH}_{4}{ }^{+}\right)$aplicado. 


\section{CONCLUSÕES}

$\mathrm{O}$ uso de menores doses de dejeto líquido de suínos minimiza as perdas de $\mathrm{N}$ por volatilização de amônia. Os picos de perda ocorreram nas primeiras horas após a aplicação indicando que, quando possível, a sua incorporação seria uma alternativa à diminuição nas perdas de $\mathrm{N}$ por volatilização. $\mathrm{O}$ horário de aplicação do dejeto não se mostrou uma alternativa consistente para diminuir as perdas de $\mathrm{N}$ por volatilização de amônia.

\section{REFERÊNCIAS BIBLIOGRÁFICAS}

BASSO, C.J. Perdas de nitrogênio e fósforo com aplicação no solo de dejetos líquidos de suínos. 2003. 125f. Tese (Doutorado em Agronomia) Programa de Pós-graduação em Agronomia, Universidade Federal de Santa Maria.

BEAUCHAMP, E.G.; KIDD, G.E.; THURTELL, G. Ammonia volatilization from liquid dairy cattle manure in the field. Canadian Journal of Soil Science, v.62, n.1, p.11-19, 1982 .

BLESS, H-G.; BEINHAUER, R.; SATTELMACHER, B. Ammonia emission from slurry applied to wheat stubble and rape in North Germany. Journal of Agricultural Science, v.117, n.1, p.225-231, 1991.

BRUNKE, R. et al. Effects of meteorological parameters on ammonia loss from manure in the field. Journal of Environmental Quality, v.17, n.3, p.431-436, 1988.

DA ROS, C. Dinâmica do carbono e do nitrogênio com o uso de uréia na sucessão aveia preta/milho no sistema plantio direto. 2004. 156f. Tese (Doutorado em Ciência do Solo) - Programa de Pós-graduação em Ciência do Solo, Universidade Federal de Santa Maria.

GORDON, R. et al. Field estimates of ammonia volatilization from swine manure by a simple micrometeorological technique. Canadian Journal of Soil Science, v.68, n.2, p.369-380, 1988.
LARA, C.W.A.R.; TREVELIN, P.C.O. Eficiência de um coletor semi-aberto estático na quantificação de $\mathrm{NH}$ volatilizado da uréia aplicada ao solo. Revista Brasileira de Cî̉ncia do Solo, v.14, n.1, p.345-352, 1990.

MACKENZIE, A.F.; TOMAR, S.J. Effect of added monocalcium phosphate monohydrate and aeration on nitrogen retention by liquid hog manure. Canadian Journal of Soil Science, v.67, n.3, p.687692, 1987.

MOAL, J.F. et al. Ammonia volatilization following surfaceapplied pig and cattle slurry in France. Journal of Agricultural Science, v.125, n.2, p.245-252, 1995.

NÖMMIK, H. The effect of pellet size on the ammonia loss from urea applied to forest soil. Plant \& Soil, v.39, n.2, p.309-318, 1973.

SCHERER, E.E.; BALDISSERA, I.T.; DIAS, L.F.X. Potencial fertilizante do esterco líquido de suínos da região Oeste Catarinense. Agropecuária Catarinense, v.8, n.1, p.35-39, 1995.

SCHERER, E.E.; AITA, C.; BALDISSERA, I.T. Avaliação da qualidade do esterco da região Oeste Catarinense para fins de utilização como fertilizante. Florianópolis : Empresa de Pesquisa Agropecuária e Difusão de Tecnologia de Santa Catarina, 1996. 46p. (Boletim Técnico, 79).

SOMMER, S.G.; OLSEN, J.E. Effects of dry matter content and temperature on ammonia loss from surface applied cattle slurry. Journal of Environmental Quality, v.20, n.3, p.679683,1991

SOMMER, G.S. et al. Ammonia volatilization from pig slurry applied with trail hoses or broad spread to winter wheat: effects of crop developmental stage, microclimate, and leaf ammonia absorption. Journal of Environmental Quality, v.26, n.4, p.11531160, 1997.

TEDESCO, M.J. et al. Análise de solo, plantas e outros materiais. Porto Alegre : Departamento de Solos, UFRGS, 1995. $174 \mathrm{p}$.

THOMPSON, R.B.; PAIN, B.F.; REES, Y.J. Ammonia volatilization from cattle slurry following surface application to grassland. Plant \& Soil, v.125, n.1, p.119-128, 1990. 